\title{
Problems of Electric Power Systems Flexibility: Definitions and Measures
}

\author{
Nikolai I. Voropai ${ }^{1,2}$ \\ ${ }^{1}$ Melentiev Energy Systems Institute of Siberian Branch of the Russian Academy of Sciences \\ ${ }_{2}^{2}$ Irkutsk National Research Technical University \\ Irkutsk, Russia \\ voropai@isem.irk.ru
}

\begin{abstract}
The paper focuses on flexibility as a new property of electric power systems (EPSs). The definitions of EPS flexibility are analyzed. The enhancement of the flexibility of generation, network, load, protection and control systems is considered as measures to provide EPS flexibility. Current trends in changes in EPS flexibility are discussed. The necessity of a comprehensive study on negative and positive factors to increase EPS flexibility is emphasized.
\end{abstract}

Keywords- electric power systems, flexibility, definition, measures, comprehensive study

\section{INTRODUCTION}

Electric power systems (EPSs) are constantly evolving complex entities that use innovative electricity production, transmission, distribution and storage technologies, and that are affected by a variety of objective factors. The process of the evolution alters the properties of these systems and causes the need to update new properties of the transformed power systems. This is associated with the new problems arising in the operation of these systems and, accordingly, with the need to use new means to ensure normal operation of EPS.

\section{DEFINITIONS}

In the past few years, authors of some publications have been actively discussing a new term reflecting the transformation of EPS properties. This is flexibility $[1-3$, etc.]. Let us consider several definitions of EPS flexibility.

Flexibility of operation - the ability of a power system to respond to a change in demand and supply - is a characteristic of all power systems with high levels of grid-connected variable renewable energy (primarily, wind and solar) [1].

Operational flexibility is the capability of the EPS to absorb disturbances in order to maintain a secure operating state. Locational flexibility is the operational flexibility available at a given bus in the grid [2].

As more variable resources are integrated into EPS, supply and demand uncertainty increases dramatically. This requires the system to have the ability to react to a sudden change and accommodate new status within acceptable time period and cost [3].

Technical system is flexible when the design parameters are determined so that with the aid of control system it can meet all requirements and constraints at each time instant of operation under any uncertain factors [4].

As we see, there is a common understanding of flexibility as an important EPS property. Generally, taking into account the basic sense of the abovementioned and other papers, it is possible to consider the following definition and content of the EPS flexibility.

The flexibility of the electric power system is its ability to maintain normal state when exposed to internal (sudden changes and fluctuations of load, power flows through tie lines, and generation) and external (sudden disturbances) random (undetermined, uncertain) impacts. Sudden changes in load are caused by its random irregular fluctuations due to the variability in electricity demand of many consumers and activity of consumers managing their own electricity consumption online. Power flows along tie lines can be changed online unpredictably under the influence of random irregular load fluctuations and changes in electricity prices and contracts for electricity sale/purchase in the spot (balancing) electricity market. Random changes in generated power are characteristic of renewable energy sources (primarily, wind turbines, as well as small hydropower and photovoltaic plants). Sudden disturbances include a wide range of different effects: short circuits for various reasons, failures and false operation of protection and emergency devices, erroneous personnel actions, etc.

\section{MEASURES}

The flexibility of an electric power system can be provided through the capabilities to increase the flexibility of generation, electrical network and load, and to use the possibilities of protection and control system. Let us discuss these ways in more detail.

- Frequency characteristics of speed regulators and inertia of rotating machines play an important role in ensuring flexibility of traditional generation as the measures of selfadaptation to uncertain factors [5]. Generation flexibility can be provided by increasing the speed of units loading and unloading and their range, by maintaining the necessary level of operational generation reserve, and by 
increasing reliability of fuel supply to power plants [1 - 3].

- Flexibility of transmission and distribution electrical networks can be enhanced by eliminating weak points in the network and improving the transfer capabilities of tie lines, in particular, by applying smart grid technologies providing the required level of transfer capability margins. There are new opportunities to increase flexibility of active electrical networks by dynamic and adaptive topology reconfiguration [6, etc.].

- Load flexibility can be increased by using voltage and frequency regulation effects as the measure of self-adaptation to uncertain factors [5]; by involving load management and using local electricity storages, distributed generation facilities at consumers, and other local devices $[1,2,7$, etc.]. New possibilities of increasing load flexibility can be used by prosumers [8].

- Integrated multi-energy systems open up new additional possibilities of increasing EPS flexibility through the use of heat storages, heat pumps and electrical boilers [9, 10, etc.]. Innovative integrated electric power and gas system is a good solution to meet electric power system flexibility requirements by using more effective distributed generation units $[10$, $11]$.

- Efficient protection and control systems play a key role in increasing EPS flexibility [12, 13], including optimization and control of EPS in a multi-energy system [14]. The effectiveness of the EPS control system can be enhanced by improving the forecast accuracy of state variables, reducing the time spent on generation of control actions and increasing their frequency, etc.) $[1-3]$.

Modern electric power systems are characterized by a sufficient level of flexibility owing to their abovementioned internal properties of self-adaptation, selfstabilization, and control of operating conditions. Selfadaptation of an electric power system, i.e. its ability to withstand internal and external destabilizing impacts, is achieved due to the existence of load-based voltage and frequency regulation effects and frequency characteristics of generation. Another factor ensuring the self-adaptation of electric power system is its inertia determined by the inertia of rotating mechanical mass of rotors of power generators. Owing to these effects, electric power system can adapt to a certain extent to sudden changes in its state and external impacts, meanwhile the control systems cope with these changes and impacts when the state variables of the system go beyond certain limits, by bringing these variables within the specified boundaries of the feasibility region of EPS operation [5].

\section{TRENDS IN EPS DEVELOPMENT}

The electric power systems of the 21-st century are expected to face dramatic changes in their internal structure and properties that will significantly reduce the level of self-adaptation and resilience, and hence the flexibility of these systems. Internal impacts are associated with the massive use of power electronics and rectifier-inverter systems for connecting highfrequency small gas-turbine plants, wind turbines, photovoltaic systems, energy storage devices, DC lines and links, frequency-controlled motors, and local rectifiers of many electrical loads to electric power systems. This significantly reduces the abovementioned load-based voltage and frequency regulation effect and generation-based frequency regulation effect, as well as the EPS inertia. On the other hand, the planned rapid growth in the number of intermittent generators, especially wind turbines, will lead to a significant increase in the negative impact of power output fluctuations on the power system selfadaptation capabilities, and, accordingly, reduce their flexibility [5].

At the same time, the control systems of many devices with power electronics (FACTS, energy storage systems, DC lines and links, etc.) are highly efficient and their wide use will significantly increase the controllability of future electric power systems.

\section{CONCLUSION}

Thus, there is a tendency towards a reduction in the flexibility of future power systems, an increase in the level of instability of these systems, and at the same time, towards an improvement in their controllability. The combination of individual factors and their levels vary depending on EPS structure, however, the above-mentioned general trends are the same. The prevalence of negative factors and underestimation of positive ones in the process of electric power system development and operation will lead to an unacceptable reduction in the flexibility of these systems, an increase in their failure rate, a decrease in the reliability of electricity supply to consumers and deterioration in power quality. Thorough comprehensive studies are necessary to deal with the negative factors and effectively use the positive ones.

\section{ACKNOWLEDGMENT}

This work was supported by Russian Scientific Foundation, project № 19-49-04108

\section{REFERENCES}

[1] Cochran J., Miller M., Zinaman O., Milligan M., e.a., "Flexibility in $21^{\text {st }}$ Century power systems", $21^{\text {st }}$ Century Power Partnership, Denver, USA, Clean Energy Ministerial, 2014, pp. 1-14.

[2] Bucher M.A., Delikaraoglou S., Heussen K., Pinson P., Andersson G., "On quantification of flexibility in power systems", 2015 IEEE Power Tech, Eindhoven, Netherlands, June 29 - July 2, 2015, 6 p.

[3] Jinye Zhao, Tongxin Zheng, Litvinov E., "A unified framework for defining and measuring flexibility in power system”, IEEE Trans. on Power Systems, 2016, Vol. 31, No. 1, pp. 339-347. 
[4] Volin Yu.M., Ostrovskiy G.M., "Flexibility analysis of complex technical systems under uncertainty", Avtomatika I Telemehanika (Remote Control), 2002, No. 7, pp. $92-106$.

[5] Voropai N.I., Osak A.B., "Electric power systems of the future", Energeticheskaya Politika, 2014, Issue 5, pp. 22 - 29 (in Russian).

[6] Sun Hongbo, Wang Yishen, Nikovski D., Zhang Jinyun, "Flex-Grid: A dynamic and adaptive configurable power distribution system", 2015 IEEE Power Tech, Eindhoven, Netherlands, June 29 - July 2, 2015, 6 p.

[7] Schuitema G., Ryan L., Aravena C., "The consumer's role in flexible energy systems", IEEE Power and Energy Magazine, 2017, Vol. 15, No. 1, pp. $53-60$.

[8] Casey E., Beaini S., Pabi S., Zammit K., Amarnath A., "The triple bottom line for efficiency", IEEE Power and Energy Magazine, 2017, Vol. 15, No. 1, pp. $34-42$.

[9] Kiviluoma J., Heinen S., Qazi H., Madsen H., Strbac G., etc., "Harnessing flexibility from hot and cold", IEEE Power and Energy Magazine, 2017, Vol. 15, No. 1, pp. $25-33$.

[10] Chen Xinyu, Kang Chongquing, O'Maley M., Xia Qing, etc., "Increasing the flexibility of combined heat and power for wind power integration in China: Modeling and implication", IEEE Trans. on Power Systems, 2015, Vol. 30, No. 4, pp. $1848-1857$.

[11] Heinen S., Hewicker C., Jenkins N., McCalley J., O’Malley M., etc., "Unleashing the flexibility of gas", IEEE Power and Energy Magazine, 2017, Vol. 15, No. 1, pp. 16 - 24.

[12] Gopalan S., Sreeram V., Iu H., Mishra Y., "A flexible protection scheme for an islanded multi-microgrid", $4^{\text {th }}$ IEEE PES Innovative Smart Grid Technologies Europe, Copenhagen, October 6-9, $5 \mathrm{p}$.

[13] Voropai N.I., Efimov D.N., Kolosok I.N., Kurbatsky V.G., Glasunova A.M., Korkina E.S., Tomin N.V., Panasetsky D.A., "Intelligent control and protection in the Russian electric power system", Application of Smart Grid Technologies, London, UK, Elsevier-Academic Press, 2018, pp. $61-140$.

[14] Dall'Anese E., Mancarella P., Monti A., "Unlocking flexibility”, IEEE Power and Energy Magazine, 2017, Vol 15 , No. 1 , pp. $43-52$ 